\title{
EFEITO DO HORÁRIO DE COLETA SOBRE A VIABILIDADE POLÍNICA EM Physalis peruviana
}

\author{
$\underline{\text { Alismário Leite da Silva }}{ }^{1}$; Adriana Rodrigues Passos ${ }^{2}$; Keylla Souza dos Santos ${ }^{3}$; \\ Cassio Gyovanne de Aquino Amorim ${ }^{4}$ \\ 1. Estagiário no Programa de Estágio Voluntário de Iniciação Científica (PEVIC), Graduando em Agronomia, \\ Universidade Estadual de Feira de Santana, e-mail: alismarioagronomo@ hotmail.com \\ 2. Orientadora, Departamento de Biologia, Universidade Estadual de Feira de Santana, e-mail: \\ adrianarpassos@yahoo.com.br \\ 3. Doutoranda em Recursos Genéticos Vegetais, Universidade Estadual de Feira de Santana, e-mail: \\ keyllasouzas@yahoo.com.br \\ 4. Participante do projeto, Graduando em Agronomia, Universidade Estadual de Feira de Santana, e-mail: \\ cassiogyovanneagro@ hotmail.com
}

PALAVRAS-CHAVE: Uchuva; Grãos de pólen; Viabilidade.

\section{INTRODUÇÃO}

A Physalis peruviana L. é a espécie mais conhecida do gênero Physalis. O seu centro de origem e diversificação, provavelmente, encontra-se nos Andes Sulamericanos, principalmente, na Colômbia, Peru e Equador (MEDINA, 1991). Posteriormente esta espécie foi introduzida na África e Índia, onde se verificou a existência de mais de 80 ecótipos em todo o mundo (GONZÁLEZ et al., 2008).

Esta espécie é conhecida popularmente como Uchuva e se destaca dentro do gênero Physalis em decorrência da produção de seu fruto que é amplamente comercializado em diversos países como no Equador, China, África do Sul, Nova Zelândia, Austrália, Kenia, Havaí, Índia, Malásia e Colômbia que atualmente é considerada a maior produtor (NOVOA et al., 2006). Seu fruto é exótico e possui sabor adocicado, com bom conteúdo de vitaminas $\mathrm{A}$ e $\mathrm{C}$, minerais como $\mathrm{Fe}$ e $\mathrm{P}$, além de inúmeras propriedades medicinais (CHAVES et al., 2005).

Suas flores são solitárias, pedunculadas e hermafroditas, derivam da axila dos ramos e estão constituídas de uma corola amarela em forma tubular com uma mancha roxa na base das pétalas. A floração dura aproximadamente três dias. Na Physalis peruviana prevalece a alogamia, em que as flores são facilmente polinizadas pelos insetos e por ventos, apresentando também autopolinização (LAGOS et al., 2008).

A viabilidade do pólen é um parâmetro de grande importância no estudo de plantas, pois além de evidenciar a potencialidade reprodutora masculina da espécie, contribui em estudos taxonômicos, ecológicos, palinológicos, fornecendo informações básicas para a aplicação prática na conservação genética, bem como na agricultura, para o planejamento de algum tipo de melhoramento ou cultivo (ALEXANDER, 1980; GUINET 1989). Segundo Souza et al. (2002), a viabilidade e a germinabilidade polínica constituem-se em fatores importantes para o melhoramento de plantas, pois em algumas espécies cada grão de pólen leva consigo os materiais genéticos resultantes da recombinação, fazendo com que estas plantas transmitam à próxima geração genótipos amplamente diversificados, tamanha a probabilidade de diferentes combinações entre os alelos que ocorre na meiose.

Sendo assim, o presente trabalho teve como objetivo avaliar a taxa de fertilidade da planta, ao longo do dia, a fim de determinar o horário com maior disponibilidade dos grãos de pólen viáveis em Physalis peruviana.

\section{MATERIAL E MÉTODOS OU METODOLOGIA}


O experimento foi conduzido na Unidade Experimental Horto Florestal, pertencente à Universidade Estadual de Feira de Santana (UEFS), Feira de Santana, Bahia, e as avaliações realizadas nos laboratórios que se encontram na Unidade. Sementes de Physalis peruviana foram semeadas em bandejas e acondicionadas em casa de vegetação. Após, aproximadamente 60 dias, as mudas foram transplantadas para vasos com capacidade de 10 litros, contendo Terra vegetal e o substrato comercial Techns Vivato® (casca de pinus bio-estabilizada, vermiculita, moinha de carvão vegetal, água e espuma fenólica) na proporção 3:1.

O teste de viabilidade de pólen foi realizado segundo a técnica descrita por Linsley e Cazier (1963), onde anteras de flores abertas foram coletadas no período de 8:00, 11:00, 14:00 e 17:00 h e dispostas em lâminas contendo carmim acético 2\%, que indica a integridade cromossômica. Com auxílio de um bisturi foram realizadas suaves compressões para liberação dos grãos de pólen e, então, o material foi coberto com lamínula e observado em microscópio. Foram confeccionadas vinte lâminas das quais foram contabilizados 400 grãos de pólen por lâmina.

A viabilidade do pólen foi determinada de acordo com o nível de coloração: pólen corado de vermelho como viável e com a cor verde-amarelado ou incolor como não-viáveis. A porcentagem de grãos de pólen viáveis foi determinada de acordo com a fórmula:

$$
\text { Viabilidade do pólen }(\%)=\underline{N^{\circ} \text { de grãos de pólen corados }} \times 100
$$

$$
\mathrm{N}^{\circ} \text { de grãos pólen total }
$$

Os resultados foram submetidos à análise de regressão utilizando o software estatístico SISVAR (FERREIRA, 2008).

\section{RESULTADOS E/OU DISCUSSÃO (ou Análise e discussão dos resultados)}

Foram observadas células ainda em fase de divisão de meiose e polens imaturos em meio aos grãos de pólen avaliados, do mesmo modo que nas avaliações dos meiócitos foram observadas fases variadas em um mesmo campo. Ainda, neste estudo, pode-se observar, apenas em alguns grãos de pólen, a presença de pollenkit (Figura 1).

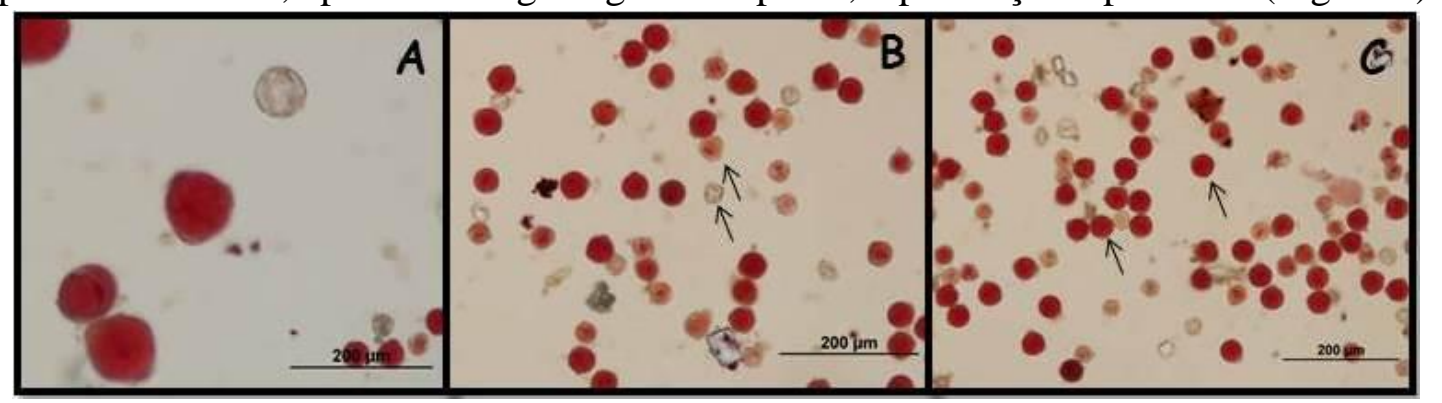

Figura 1: Grãos de pólen de Physalis peruviana corados com Carmim acético a 2\%. A) Grão de pólen viável e inviável. B) Grãos de pólen viáveis e setas indicam grãos inviáveis e meiócitos. C) Grãos de pólen viáveis (seta).

A análise de regressão para a variável horário mostrou que o melhor ajuste foi o linear, demonstrando diferenças significativas a $1 \%$ de probabilidade e sendo observada alta correlação entre as médias da viabilidade de cada horário, com $\mathrm{R}^{2}$ de 95,88 \%. Para as avaliações de viabilidade do pólen, em estádio em antese, para diferentes horários de observação, observou-se maior viabilidade de pólen no primeiro horário, as 08:00 horas da manhã, com 96,45\% (Figura 2). A taxa de viabilidade, encontrada neste estudo, para a espécie foi considerada alta, pois segundo Auler et al. (2006) a viabilidade do pólen acima de $90 \%$ é considerada alta. Segundo Biondo e Battistin (2001), a elevada taxa de viabilidade pode indicar alto potencial de fertilidade dos gametas masculinos. Os 
resultados obtidos, neste estudo, revelam que os gametas masculinos de $P$. peruviana tem alto potencial de fertilidade, garantindo assim a fecundação quando estes alcançam o óvulo. Após esse horário, foi observado decréscimo na viabilidade no decorrer do dia, onde nos horários 2 (11:00 horas) e 3 (14:00 horas) houve reduções de 6,48\% e 8,24\%, respectivamente, com relação ao primeiro horário. No entanto, foi constatado um uma redução mais acentuada no horário 4 (17:00 horas), de 14,93\% (82,05\% de viabilidade) em relação ao horário de 08:00 horas. Estudos realizados por Costa et al. (2012), onde foram avaliados os efeitos do horário de coleta de grãos de pólen para variedades de milho (Zea mays), foi observada uma redução da viabilidade polínica a medida em que os horários de coleta das flores foram avançando durante o dia. Souza et al. (2002) também constatou em seus estudos que a medida em que o tempo avança a viabilidade do grão de pólen é reduzida e assim diminui a taxa de fertilidade da planta

Fatores bióticos e abióticos podem ter sido responsáveis por essa variação na taxa de viabilidade polínica, mas não chegaram a comprometer a fertilidade da $P$. peruviana, visto que a menor viabilidade encontrada apresentou valores acima de $70 \%$, o que é considerada uma alta viabilidade (SOUZA et al., 2002). Desta forma é de fundamental importância estabelecer o melhor horário para coleta dos grãos de pólen, pois estes precisam ser capazes de fertilizar a planta receptora e ter a capacidade de formar o tubo polínico. Sendo assim, estudos que determinem o melhor horário de coleta são de extrema importância em trabalhos de melhoramento genético que visem hibridação, a fim de realizar cruzamentos com maior eficiência. Os trabalhos que indicam o melhor horário de coleta do pólen que alcance um maior percentual de viabilidade, principalmente em processos de hibridação, bem como saber a potencialidade do gameta masculino.

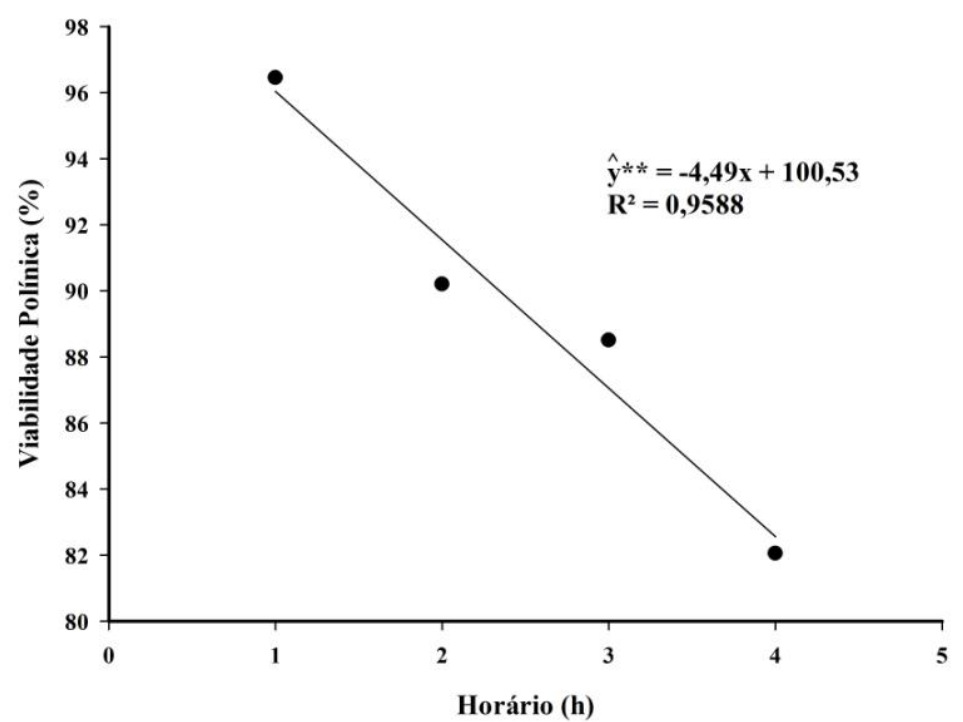

Figura 2: Viabilidade polínica de flores abertas em plantas de $P$. peruviana avaliadas em diferentes horários durante o dia.

** significativo - análise de variância $(\mathrm{p}<0,05)$.

\section{CONSIDERAÇÕES FINAIS (ou Conclusão)}

- Apesar de não comprometer as taxas de fertilidade da planta, observa-se que o fator horário apresentou influencia na viabilidade dos grãos de pólen de Physalis peruviana;

- Para Physalis peruviana recomenda-se a coleta dos grãos de pólen as 8:00 h, garantindo assim maior eficiência de cruzamentos em programas de melhoramento. 


\section{REFERÊNCIAS}

AULER, N. M. F.; BATTISTIN, A.; REIS, M. S. Número de cromossomos, microsporogênese e viabilidade do pólen em populações de carqueja [Baccharis trimera (Less.) DC.] do Rio Grande do Sul e Santa Catarina. Revista Brasileira de Plantas Medicinais, v.2, n.8, p.55-63. 2006.

ALEXANDER, M.P. A. Versatile stain for pollen fungi, yeast and bacterium. Stain Tecnology, v.1, n.5, p.13-8, 1980.

BIONDO, E. \& BATTISTIN, A. Comparação da eficiência de diferentes corantes na estimativa da viabilidade de grãos de pólen em espécies dos gêneros Eriosema (DC.) G. Don e Rhynchosia Lour (Leguminosae - Faboideae), nativas na Região Sul do Brasil. Bioikos 15(1): 39-44. 2001.

COSTA, A.; ROMANI, I.; MAGALHÃES, V. J.; BERTI, F.L.; MARTINS, J. W.; GONELA, A. Efeito do horário de coleta sobre a viabilidade do pólen de Milho (Zeamays L.). XXIX CONGRESSO NACIONAL DE MILHO E SORGO. ÁGUAS DE LINDÓIA. Revista Brasileira de Milho e Sorgo. 2012.

CHAVES, A. C. SCHUCH, M. W. ERIG, A. C. Estabelecimento e multiplicação in vitro de Physalis peruviana L. Revista Ciência Agrotécnica, v.29, p.1281-1287, 2005.

FERREIRA, D. F. Sisvar: um programa para análise e ensino de estatística. Revista Symposium, v.6, p. 36-41, 2008.

GONZÁLEZ OT; TORRES JMC; CANO CIM; ARIAS ML; ARBOLEDA AAN. Caracterización morfológica de cuarenta y seis acessiones de uchuva (Physalis peruviana L.), in Antioquia (Colombia). Revista Brasileira de Fruticultura. V. 30, p. 708-715, 2008

GUINET, P. H. Advances in legume biology: struture evolution, and biology of pollen in Leguminosae. St. Louis: Missouri Botanical Garden, 842p. 1989.

LAGOS, T. C. B.; VALEJO, F.A.C.; CRIOLLO, H.E.; MUÑOZ, J.E.F. Biologíareproductiva de lauchuva. ActaAgronómicaColombiana, Palmira, v. 57, n.2, p.81-87, 2008.

MEDINA, E. El cultivo de la Uchuva tipo exportación.Revista Agricultura Tropical, vol. 28, n. 2, p 55-58, 1991.

NOVOA, R. H., BOJACÁ, M., GALVIS, J. A., FISCHER, G. La madurez del fruto y el secado del cáliz influyen en el comportamiento poscosecha de la uchuva, almacenada a $12{ }^{\circ} \mathrm{C}$ (Physalis peruviana L.). Revista Agronomía Colombiana, v. 24, n.1, p 77-86, 2006.

SOUZA M. M.; PEREIRA, T. N. S.; MARTINS, E. R. Microsporogênese e microgametogênese associadas ao tamanho do botão floral e da antera e viabilidade polínica em maracujazeiro-amarelo (Passiflora edulisSims f. flavicarpadegener). CiênciaAgrotêcnica., Lavras. V.26, n.6, p.1209-1217, nov./dez., 2002. 